\title{
Análise do líquido broncoalveolar de equinos portadores de doença inflamatória das vias aéreas
}

\author{
Evaluation of bronchoalveolar fluid of horses with inflammatory airway disease
}

\author{
Daniel Augusto Barroso LESSA ${ }^{1}$; Maria Luisa Loredo de Abreu JORGE ${ }^{2}$; Eduardo Borges VIANA ${ }^{3}$; \\ Nayro Xavier de ALENCAR ${ }^{1}$; Wilson Roberto FERNANDES ${ }^{4}$ \\ ${ }^{1}$ Departamento de Patologia e Clínica Veterinária da Faculdade de Veterinária da Universidade Federal Fluminense, Niterói-RJ, \\ Brasil \\ ${ }^{2}$ Major Veterinário, Policia Militar do Estado do Rio de Janeiro, Rio de Janeiro-RJ, Brasil \\ ${ }^{3}$ Médico veterinário autônomo, Niterói-RJ, Brasil \\ ${ }^{4}$ Departamento de Clínica Veterinária da Faculdade de Medicina Veterinária e Zootecnia da Universidade de São Paulo, São \\ Paulo-SP, Brasil
}

\begin{abstract}
Resumo
Objetivou-se caracterizar o perfil citológico broncoalveoar de equinos de policiamento portadores assintomáticos de Doença Inflamatória de Vias Aéreas (DIVA). Utilizaram-se 17 equinos adultos, machos e fêmeas, com idade entre 11 e 24 anos. Os animais que constituíram o grupo controle (oito) apresentaram-se normais ao exame físico, à endoscopia e à mensuração da diferença máxima de pressão intrapleural. No lavado broncoalveolar a contagem deveria ser de até $4 \%$, 0,7\%,3,3\% para neutrófilos, eosinófilos e células epiteliais e entre 17,0 e 56,7\%, 29 e 75,7\%, 0,7 e 13,7\% para linfócitos, macrófagos e mastócitos, respectivamente. O grupo considerado doente (nove animais) apresentou achados compatíveis com afecções do trato respiratório posterior, pelo menos à endoscopia, além de uma contagem de neutrófilos maior que $5 \%$ e menor que $25 \%$. O quadro assintomático de doença inflamatória das vias aéreas caracterizou-se por infiltrado neutrofílico, discreta redução no número de macrófagos, aumento no número de macrófagos espumosos, discreto infiltrado eosinofílico e aumento marcante no número de células epiteliais. Em face do caráter assintomático dessa enfermidade nos equinos de policiamento, a utilização do LBA como método de diagnóstico e acompanhamento é fundamental, pois permite reconhecer, tratar e determinar uma utilização mais racional desses animais, de modo a melhorar a qualidade de vida e prolongar a utilização dos mesmos em serviço.
\end{abstract}

Palavras-chave: Citologia. Doença Inflamatória de Vias Aéreas. Equinos. Lavado broncoalveolar

\begin{abstract}
The aim of this study was to characterize the cytology profile of bronchoalveolar lavage from police horses with asymptomatic Inflammatory Airway Disease (IAD). Seventeen adult horses, males and females, with ages ranging from 11 to 24 years old were utilized. The control group (eight horses) presented vital signs within the physiologic range, normal pulmonary percussion and auscultation, no abnormalities at respiratory endoscopy and at the measurement of the maximal intra-pleural pressure difference. The cell count of bronchoalveolar lavage (BAL) should be up to $4 \%, 0.7 \%$, $3.3 \%$ to neutrophil, eosinophil and epithelial cell, and ranging of 17.0 to $56.7 \%, 29$ to $75.7 \%, 0.7$ to $13.7 \%$ to lymphocytes, macrophages and mast cell, respectively. The diseased group (nine animals) presented findings compatible with lower airway disease, at least during endoscopy and showed a neutrophil counts above $5 \%$ and below $25 \%$. Asymptomatic IAD was characterized by neutrophilic infiltrate, discrete reduction in macrophage count with increased number of foamy macrophages and discrete eosinophilic infiltrate and marked increase in the number of epithelial cells. Due to the asymptomatic character of IAD in police horses, BAL is the preferred diagnostic and follow-up method since it allows recognition of the disease, evaluation of treatment and helps the implementation of a graded and rational work regime that aims at improving welfare of those animals as well as extending their usage as patrolling horses.
\end{abstract}

Keywords: Equine. Inflammatory airway disease. Cytology. Bronchoalveolar lavage. 


\section{Introdução}

As doenças respiratórias na espécie equina representam uma importante causa de prejuízo à saúde e resultam em grande impacto econômico em função da queda de desempenho ou até mesmo pelo afastamento das atividades esportivas. Dentre estas afecções, a doença inflamatória das vias aéreas (DIVA) é particularmente importante em grandes centros urbanos, como a cidade do Rio de Janeiro, em função da elevada porcentagem de animais que apresentam esta enfermidade ${ }^{1} \mathrm{e}$ por muitas vezes a enfermidade manifestar-se de forma discreta ou assintomática ${ }^{2,3}$, dificultando o diagnóstico e por conseguinte, um tratamento preciso. Fatores de risco para a DIVA em grandes centros urbano incluem a necessidade de manter os animais estabulados e a exposição a elevados índices de poluição do ar.

Esta síndrome é caracterizada por inflamação de menor gravidade que a obstrução recorrente das vias aéreas (ORVA) e afeta principalmente animais jovens de corrida. Clinicamente os animais não apresentam dificuldades respiratórias visíveis, ou sinais de doenças sistêmicas assim como a diferença máxima de pressão intrapleural ( $\Delta \mathrm{Ppl}$ máxima) permanece inalterada. Porém apresentam evidências de inflamação de vias aéreas, tal como acúmulo de secreção mucoide e de células inflamatórias, que podem estar acompanhadas de tosse e evidência de baixo desempenho ${ }^{4}$.

Diferente da DIVA, a Obstrução Recorrente das Vias Aéreas é considerada uma síndrome de animais mais velhos (acima de seis anos), apresentando evidências de obstrução de vias aéreas caracterizada por uma $\Delta \mathrm{Ppl}$ máxima acima de $15 \mathrm{~cm}$ de $\mathrm{H}_{2} \mathrm{O}$ e infiltrado neutrofílico acima de $25 \%$ no lavado broncoalveolar (LBA) ${ }^{5}$.

O LBA é um método sensível para o diagnóstico de doenças inflamatórias não infecciosas das vias aéreas posteriores dos equinos ${ }^{6}$. Utilizando esta metodologia, vários trabalhos já foram realizados no exterior. No Brasil, algumas pesquisas foram conduzidas com animais de policiamento. Na Cidade do Rio de Ja- neiro, em um grupo de 35 animais de policiamento, foi detectada obstrução recorrente das vias aéreas (ORVA) em 60\% dos animais estudados, porém 100\% dos animais examinados apresentaram algum estado inflamatório pulmonar, caracterizado por infiltrado neutrofílico acima de $10 \%{ }^{1}$. Posteriormente, nesta mesma população equina, aparentemente saudável, foi verificado que $60 \%$ das amostras de LBA apresentaram alterações compatíveis com quadros inflamatórios, sendo um desses compatível com ORVA e os demais (11) compatíveis com DIVA?

No Distrito Federal, foram analisados 24 equinos sadios distribuídos em dois grupos de doze: um grupo de animais utilizados em ronda e outro grupo constituído por animais que não estavam sendo utilizados (afastado da escala). Nos animais de ronda registraram-se valores médios percentuais $25,25 \pm 7,3$ de células escamosas, 20,2 $\pm 5,5$ células epiteliais, 22,2 $\pm 6,3$ macrófagos e 2,02 $\pm 5,77$ de eosinófilos. No grupo afastado da escala observaram-se valores médios percentuais 31,0 \pm 9,47 de células escamosas, 19,0 \pm 5,2 células epiteliais, 43,0 \pm 13,88 macrófagos e 4,0 \pm 1,52 de eosinófilos e 3,0 $\pm 1,0$ de eritrócitos 8 .

Apesar de achados citológicos compatíveis com DIVA já terem sido descritos em cavalos aparentemente sadios da Polícia Militar do Estado do Rio de Janeiro $(\mathrm{PMERJ})^{7}$ e da DIVA já ter sido clinicamente caracterizada como assintomática em animais desta população ${ }^{3}$, diante dos diferentes perfis citopatológicos que caracterizam esta enfermidade ${ }^{9}$, existe a necessidade de estabelecer o perfil citológico nestes animais. Este trabalho teve por objetivo caracterizar o perfil citológico broncoalveoar de equinos de policiamento portadores assintomáticos de doença inflamatória de vias aéreas (DIVA).

\section{Material e Método}

Foram utilizados 17 equinos adultos (11 machos e seis fêmeas) de 11 a 24 anos (média de 15,2 $\pm 3,4$ ), 
sendo oito (grupo controle) pertencentes ao $2^{\circ} \mathrm{Re}-$ gimento de Cavalaria de Guardas Andrade Neves (RCGd, RJ) e nove (grupo doente) ao Regimento de Polícia Montada do Estado do Rio de Janeiro (RPMont, PMERJ).

Os animais do grupo Controle foram mantidos semiestabulados em baias de aproximadamente $9 \mathrm{~m}^{2}$, sem cama, alimentados com 5-6 kg/animal de ração comercial com $12 \%$ de proteína bruta (PB) e $2-3 \mathrm{~kg}$ feno de Coast Cross/animal, limpos diariamente e soltos 4-6 vezes por semana. Esses animais trabalhavam diariamente em atividades esportiva ou de patrulha (trabalho moderado).

Os animais da PMERJ também foram mantidos semiestabulados, em baias de metragem $6 \mathrm{~m}^{2}$, sem cama de 6 às $15 \mathrm{~h}$ e o restante do período em solário, alimentados com $6 \mathrm{~kg} /$ animal de ração comercial com 12\% de PB e 12 kg/animal de Capim-Angola (Brachiaria mutica) cortado e oferecido no solário.

Todos os animais foram vermifugados trimestralmente e vacinados contra influenza, tétano, encefalomielite equina leste e oeste, rinopneumonite e raiva. Adicionalmente, os do grupo controle também foram vacinados contra garrotilho e leptospirose.

Nenhum dos animais de ambos os grupos estava sendo submetido a tratamento ou foi relatado sintoma de doença respiratória nos últimos dois meses. No momento do exame apresentavam-se aparentemente sadios e com valores de leucograma e fibrinogênio plasmático dentro da normalidade segundo Tyler et al. ${ }^{10}$.

Foi realizado exame físico com especial ênfase ao exame do aparelho respiratório, considerando os va- lores de referência descritos por Houston e Radostits ${ }^{11}$ para as funções vitais e por McGorum et al. ${ }^{12}$ para os resultados da percussão e ausculta pulmonar.

Avaliação endoscópica foi realizada, sem que os animais tivessem sido previamente exercitados, utilizando-se fibroscópio (Olympus modelo GIF-PQ 20, Olympus Optical do Brasil, Ltda') sendo considerados achados compatíveis com afecções do trato respiratório posterior a presença de exsudato na traqueia, com ou sem hiperemia e/ou facilidade na provocação de tosse pela presença do endoscópio nesta região ${ }^{13}$. As alterações encontradas foram classificadas de acordo com a gravidade do processo em: - (inexistente), + (leve),++ (moderada) e intensa $(+++)$.

A diferença máxima de pressão intrapleural $(\Delta \mathrm{Ppl}$ máxima) foi indiretamente aferida conforme metodologia previamente descrita ${ }^{14}$ (Venti-graph', Boeringer Ingelheim, Divisão Vetmédica). Os valores até $4 \mathrm{~cm}$ de $\mathrm{H}_{2} \mathrm{O}$ foram considerados normais ${ }^{15}$.

Os exames físicos foram realizados em duplicata com exceção de um animal de cada grupo. As endoscopias e mensurações da diferença de pressão intrapleural máxima foram realizadas de forma única.

O Grupo Controle foi constituído por animais que apresentaram resultados de normalidade para as funções vitais, $\Delta \mathrm{Ppl}$ máxima (Tabela 1 ), assim como para percussão, ausculta pulmonar e endoscopia.

De acordo com definição clínica da DIVA ${ }^{4}$, os animais do Grupo Doente Assintomático apresentaram normalidade para as funções vitais, $\Delta \mathrm{Ppl}$ máxima (Tabela 1) e percussão pulmonar. Ruído broncovesicular aumentado foi detectado em oito exames (47\%)

Tabela 1 - Resultado da avaliação das funções vitais (temperatura, frequência cardíaca e frequência respiratória) e da aferição da diferença de pressão intrapleural $(\Delta \mathrm{Ppl}$ máxima) dos equinos dos grupos Controle (sadio) e Doente (com suspeita de DIVA), apresentado na forma de média \pm 1 DP - Rio de Janeiro - 2001

\begin{tabular}{lccccc}
\hline Grupo & $\mathbf{N}$ & $\mathbf{T}\left({ }^{\circ} \mathbf{C}\right)$ & FC $(\mathbf{b p m})$ & FR (mpm) & $\begin{array}{c}\Delta \text { Ppl máxima } \\
\left(\mathbf{c m} \text { de } \mathbf{H}_{2} \mathbf{O}\right)\end{array}$ \\
\hline Controle & 15 & $37,97 \pm 0,31$ & $35,07 \pm 3,45$ & $11,87 \pm 3,42$ & $2,68 \pm 0,54$ \\
Doente & 17 & $37,61 \pm 0,25$ & $30,88 \pm 3,64$ & $13,29 \pm 3,93$ & $2,78 \pm 0,67$ \\
\hline
\end{tabular}

T: temperatura; bpm: batimentos por minuto; mpm: movimentos por minuto; $\mathrm{cm}$ : centímetros. 
e todos os animais apresentaram achados endoscópicos compatíveis com afecções do trato respiratório posterior (Tabela 2).

Os lavados broncoalveolares foram realizados em duplicata com exceção de um animal de cada grupo, com intervalos de uma semana entre as coletas. Os animais foram contidos com cachimbo e sedados com cloridrato de romifidina (Sedivet, Boehringer Ingelheim, Divisão Vetmédica), na dosagem de 0,04 $\mathrm{mg} / \mathrm{kg}$, i.v.. Os lavados foram obtidos por meio de uma sonda de silicone (Equine bronchoalveolar lavage catheter, Bivona, Smiths Medical PM, Inc.) segundo a técnica descrita na literatura ${ }^{16}$. As amostras foram consideradas adequadas quando um mínimo de $40 \%$ do volume infundido havia sido recuperado ${ }^{5}$ junto ao surfactante.
O fluído aspirado foi mantido refrigerado até o processamento, o qual foi realizado no Laboratório Clínico Veterinário da Faculdade de Veterinária da UFF/ RJ, até quatro horas após a coleta.

As características macroscópicas do lavado (coloração, turbidez, número e tamanho de partículas) foram classificadas aplicando-se um escore ${ }^{17}$ (Tabela 3) e o valor final atribuído para cada amostra foi decorrente do somatório dos valores atribuídos para cada característica.

Para a contagem diferencial de células nucleadas (CDCN), alíquotas de $200 \mu \mathrm{l}$ da suspensão celular do lba foram submetidas à citocentrifugação (Citospyn', incibrás, Fanem) à $28 g$ durante seis minutos. Nas lâminas coradas segundo o método de Rosenfeld ${ }^{18}$, foram analisados os tipos celulares após a contagem de

Tabela 2 - Alterações clínicas das vias aéreas de equinos de policiamento urbano observadas à endoscopia. Os achados encontrados foram classificados de acordo com a gravidade do processo - Rio de Janeiro - 2001

\begin{tabular}{cccccc}
\hline \multirow{2}{*}{ Animal } & \multicolumn{2}{c}{ Secreção traqueal } & \multicolumn{2}{c}{ Hiperemia } & \multirow{2}{*}{ Tosse } \\
\cline { 2 - 5 } & mucosa & hemorrágica & Laríngea & Traqueal & \\
\hline 609 & + & - & - & - & - \\
614 & + & - & - & + & ++ \\
300 & + & - & - & - & - \\
123 & + & + & - & - & - \\
627 & ++ & - & - & - & - \\
105 & + & - & - & - & - \\
682 & + & - & - & - & - \\
612 & $+{ }^{*}$ & - & + & - & ++ \\
642 & + & - & - & - & - \\
\hline
\end{tabular}

-: inexistente; +: leve; ++: moderada; +++: intensa; *: com presença de grumos.

Tabela 3 - Características macroscópicas do LBA de cavalos segundo McKane et al. ${ }^{21} \mathrm{e}$ modificado por Mori ${ }^{17}$

\begin{tabular}{cccc}
\hline \multirow{2}{*}{ Escore } & \multicolumn{3}{c}{ Característica do Lavado Broncoalveolar } \\
\cline { 2 - 4 } & Coloração & Turbidez & $\mathbf{N}^{\circ}$ e tamanho de partículas mucoides \\
\hline 0 & Ausente & Transparente & Ausente \\
1 & Rosa & Translúcido & Poucas partículas pequenas \\
2 & Vermelho & Turvo & Muitas partículas pequenas \\
3 & Vermelho escuro & Opaco & Muitas partículas grandes \\
\hline
\end{tabular}


600 células com aumento de 1000x. Foram incluídos no grupo os animais que apresentaram contagem de neutrófilos até $4 \%$, linfócitos de 17,0 a 56,7\%, macrófagos de 29 a 75,7\%, eosinófilos até $0,7 \%$, mastócitos de 0,7 a $13,7 \%$ e células epiteliais até $3,3 \%{ }^{19}$ e no grupo doente aqueles que apresentaram contagem de neutrófilos maior que $5 \%$ e menor que $25 \%{ }^{20}$

Os dados de escore foram submetidos à transformação logarítmica. As demais variáveis e as variáveis transformadas foram submetidas a análises de variância, onde foi adotado nível de significância de 5\%. as análises estatísticas foram realizadas utilizando-se o programa computacional BioEstat.

Os procedimentos experimentais que envolveram manipulação dos animais foram realizados de acordo com normas éticas.

\section{Resultados e Discussão}

A análise dos resultados revelou diferença significativa no escore $(4,07 \pm 1,39$ no grupo Doente contra 2,87 $\pm 0,64$ no Controle; $\mathrm{P}=0,0014)$; onde este aumento, no grupo doente, provavelmente se deve ao aumento da celularidade e da presença de secreções. O valor no grupo Controle estava abaixo do que já foi previamente relatado para cavalos de corrida ${ }^{21}$. Esta divergência pode estar relacionada ao fato desses autores terem trabalhado com animais sem aparentes problemas de desempenho, mas que apresentaram Hemorragia Pulmonar Induzida por Esforço e algum grau de inflamação pulmonar. Por outro lado, ficou acima do valor de 0,48 encontrado para animais hígidos $^{17}$, fato esse que pode ser devido a diferenças de celularidade nos lavados. Em animais normais, o LBA é discretamente turvo ${ }^{22}$, fato que também foi verificado neste trabalho.

Os valores relativos das contagens diferenciais dos tipos celulares estão apresentados na tabela 4, havendo diferença significativa para: neutrófilos $(\mathrm{P}<$ 0,0001), macrófagos espumosos ( $\mathrm{P}<0,0001$ ), células epiteliais ( $\mathrm{P}=0,0048)$ e macrófagos totais ( $\mathrm{P}=$ 0,0001), sendo que apenas o valor deste último tipo celular foi maior no grupo controle.

Valores de neutrófilos abaixo e acima da média encontrada nesse trabalho, para animais sadios, já foram descritos na literatura ${ }^{23,24}$. Isto pode ser explicado pelo efeito da infusão e, por conseguinte, da recuperação de diferentes volumes sobre a composição celular do LBA. Uma maior percentagem de neutrófilos e menor de mastócitos foram verificadas quando comparados volumes infundidos de 50 e $350 \mathrm{~mL}$ de solução fisiológica $0,9 \%$, sendo o volume médio recuperado respectivamente de $15,9 \pm 4,6 \mathrm{~mL}$ e $252,3 \pm 31,5 \mathrm{~mL}^{25}$.

À semelhança do que ocorreu com os linfócitos, a redução no percentual de macrófagos no grupo Doente, mesmo tendo sido significativa ( $\mathrm{P}=0,0001$ ) também pode ter sido em função de variações nas proporções das populações celulares, uma vez que os valores encontrados para ambos os grupos estão em conformi-

Tabela 4 - Resultados da contagem diferencial de células presentes no lavado broncoalveolar dos equinos dos grupos experimentais expressos em valores percentuais médios \pm 1 DP - Rio de Janeiro - 2001

\begin{tabular}{|c|c|c|c|c|c|c|c|c|c|}
\hline & Neutrófilo & Linfócito & $\begin{array}{c}\text { Total de } \\
\text { Macrófagos }\end{array}$ & Hemossiderófagos* & $\begin{array}{l}\text { Macrófagos } \\
\text { espumosos }^{\star}\end{array}$ & $\begin{array}{l}\text { Célula } \\
\text { Gigante }\end{array}$ & Eosinófilo & Mastócito & $\begin{array}{l}\text { Célula } \\
\text { Epitelial }\end{array}$ \\
\hline $\begin{array}{l}\text { Controle } \\
(n=15)\end{array}$ & $2,35 \pm 1,20^{\mathrm{a}}$ & $41,33 \pm 9,60^{\mathrm{a}}$ & $53,11 \pm 7,85^{\mathrm{a}}$ & $1,69 \pm 4,23^{a}$ & $6,00 \pm 7,15^{\mathrm{a}}$ & $0,21 \pm 0,37^{\mathrm{a}}$ & $0,42 \pm 1,02^{\mathrm{a}}$ & $2,43 \pm 2,30^{\mathrm{a}}$ & $0,23 \pm 0,43^{\mathrm{a}}$ \\
\hline \multirow{2}{*}{$\begin{array}{l}\text { Doente } \\
(n=17)\end{array}$} & $15,08 \pm 8,59 b$ & $35,91 \pm 10,43 a$ & $41,14 \pm 7,45 b$ & $1,01 \pm 2,00 \mathrm{a}$ & $25,06 \pm 13,94 b$ & $0,48 \pm 0,58 \mathrm{a}$ & $1,19 \pm 1,85 a$ & $3,19 \pm 2,28 \mathrm{a}$ & $2,98 \pm 3,46 b$ \\
\hline & $\mathrm{p}<0,0001$ & $\mathrm{p}=0,1378$ & $\mathrm{p}=0,0001$ & $\mathrm{p}=0,5573$ & $\mathrm{p}<0,0001$ & $\mathrm{p}=0,1346$ & $\mathrm{p}=0,1601$ & $\mathrm{p}=0,3599$ & $\mathrm{p}=0,0048$ \\
\hline
\end{tabular}

Letras diferentes em cada coluna representam diferenças estatisticamente significativas (ANOVA; p < 0,05). * Porcentagem em relação ao total de macrófagos. 
dade com a literatura consultada ${ }^{26}$. Porém, em cavalos utilizados em competições de trote apresentando má performance e DIVA assintomática foram descritos perfis celulares com aumentos de neutrófilos, linfócitos e macrófagos em associação ou não ${ }^{27}$.

Macrófagos alveolares de animais sadios apresentam uma discreta vacuolização citoplasmática ${ }^{28}$. Uma vez que macrófagos espumosos são compatíveis com estados de ativação e estão presentes em processos inflamatórios alérgicos pulmonares ${ }^{29}$, assim como em animais com DIVA ${ }^{21}$, o aumento destas células no grupo Doente corrobora com as informações acima e indica que realmente existe discreto processo inflamatório no trato respiratório posterior.

Células multinucleadas podem aparecer em resposta a uma irritação não específica e sugerem um processo granulomatoso ou inflamatório $\mathrm{crônico}^{30}$. A presença de tais células em animais sadios já foi assinalada ${ }^{22,31}$ e o aumento na contagem destas é considerado evidência de $\mathrm{DIVA}^{9}$. Ainda que o valor para o grupo Doente tenha sido maior (Tabela 4) a ausência de diferença significativa ( $\mathrm{P}=0,1346)$ pode ser justificada pelo fato da inflamação não ter sido tão intensa a ponto de haver necessidade de fusionamento de células para o combate aos agentes agressores.

Mesmo não havendo diferença significativa ( $\mathrm{P}=$ 0,1601 ), os valores relativos para eosinófilos no grupo Doente foram praticamente o triplo do valor para o grupo Controle. Este quadro citológico também foi descrito por outros autores ${ }^{26,29}$ quando avaliaram animais com DIVA. Nos processos inflamatórios alérgicos, o infiltrado eosinofílico é tardio em relação ao de mastócitos, dessa forma o aumento de eosinófilos nesses animais pode ser justificado em função da idade (animais maduros) e, por conseguinte, do longo tempo de exposição aos agentes etiológicos da DIVA.

$O$ aumento significativo na contagem de células epiteliais ( $\mathrm{P}=0,0048$ ) pode estar relacionado ao trauma de coleta ou às infecções virais, mas também ocorrem em casos de ORVA ou DIVA ${ }^{32}$. Este aumento pode estar relacionado a aumento na taxa de renovação celular do epitélio respiratório, decorrente do processo inflamatório instalado.

Ainda que as diferenças encontradas possam ter ocorrido em função dos locais onde os animais foram mantidos (Regimento de Cavalaria de Guardas versus Regimento de Polícia Montada), a semelhança no manejo, no padrão racial (mestiços) e na idade; além da proximidade geográfica dos quartéis, e por conseguinte mesma condição climática atmosférica, minimiza esta possibilidade. Além disso, como já foram previamente encontrados altos percentuais de animais apresentando quadros citopatológicos compatíveis com processos inflamatórios pulmonares nessa população ${ }^{1,7}$, optou-se por utilizar os animais do RCGd para compor o grupo controle.

O exercício físico facilita a detecção das manifestações clínicas importantes para o direcionamento do diagnóstico. No policiamento urbano geralmente os animais não são exigidos fisicamente, portanto, mesmo que apresentem quadros inflamatórios como os aqui diagnosticados, esses podem não demonstrar manifestações clínicas. Esta situação é semelhante ao que foi verificado para animais de passeio, onde um grau relativamente moderado de inflamação não foi clinicamente detectável ${ }^{33}$.

A intensa exposição a poluentes atmosféricos, durante o policiamento urbano, é provavelmente um importante fator de risco para a enfermidade aqui diagnosticada. Diferentemente do que foi observado por Costa e Macoris ${ }^{8}$, que não encontram diferenças entre os animais de ronda e os baixados, este fato pode estar relacionado às melhores condições ambientais do Distrito Federal e/ou a metodologia de coleta empregada, uma vez que os valores encontrados pelos autores diferem inclusive dos internacionalmente aceitos para cavalos sadios 5 .

Os trabalhos de pesquisa já desenvolvidos no Brasil ${ }^{1,3,7,8,31}$ reforçam observações prévias sobre a sensibilidade do LBA para o diagnóstico de enfermidades 
das vias aéreas posteriores de equinos ${ }^{6}$. Estes fatos representam um avanço na abordagem diagnóstica dentro da clínica médica de equinos em nosso País

Embora na maioria das vezes animais de policiamento não sejam exigidos fisicamente, algumas situações como controle de multidões em grandes eventos exige esforço físico do animal e nestas situações, uma plena condição respiratória é importante para o bom desempenho da atividade. Além disso, enfermidades inflamatórias pulmonares pré-existentes também podem agravar e prolongar o curso de quadros infecciosos. Estes fatos podem vir a provocar um descarte precoce e necessidade de reposição do animal. Portanto,

\section{Referências}

1. AMARAL, P. C.; GRAÇA, F. A. S.; VIANNA, L. F. C. G.; BORGES, J. R. J.; FERREIRA, A. M.; PIRES, N. R.; VOSS, C. Doença pulmonar obstrutiva crônica em equinos da Polícia Militar do Estado do Rio de Janeiro. Revista Brasileira de Ciência Veterinária, v. 6, n. 2, p. 77-83, 1999.

2. HODGSON, J. L.; HODGSON, D. R. Inflammatory airway disease. In: LEKEUX, P. Equine respiratory disease. Ithaca: International Veterinary Information Service, 2002. Disponível em: <http://www.ivis.org/special_books/Lekeux/hodgson/ chapter_frm.asp?LA=1>. Acesso em: 11 set. 2003.

3. LESSA, D. A. B. Doença inflamatória das vias aéreas (DIVA) em equinos de policiamento na cidade do Rio de Janeiro, RJ: estudo clínico e da atividade macrofágica alveolar. 2003. $102 \mathrm{f}$. Tese (Doutorado em Clínica Veterinária) - Faculdade de Medicina Veterinária e Zootecnia, Universidade de São Paulo, São Paulo, 2003.

4. ROBINSON, N. E. Inflammatory airway disease: defining the syndrome. Conclusions of the Havemeyer workshop. Equine Veterinary Education, v. 15, n. 2, p. 61-63, 2003.

5. ROBINSON, N. E. International workshop on equine chronic airway disease. Equine Veterinary Journal, v. 33, n. 1, p. 5-19, 2001.

6. COUËTIL, L. L.; ROSENTHAL, F. S.; DENICOLA, D. B.; CHILCOAT, C. D. Clinical signs, evaluation of bronchoalveolar lavage fluid, and assessment of pulmonary function in horses with inflammatory respiratory disease. American Journal of Veterinary Research, v. 62, n. 4, p. 538-546, 2001.

7.LESSA, D. A. B.; VIANA, E. B.; ABRAMOVITC, G.; PAIVA, V. S.; FERNANDES, W. R. Aspectos citológicos do lavado broncoalveolar de equinos da Polícia Militar do Estado do Rio de Janeiro. In: CONGRESSO BRASILEIRO DE MEDICINA VETERINÁRIA, 29., 2002, Gramado. Anais... Porto Alegre: Sociedade de Veterinária do Rio Grande do Sul, 2002. CD-ROM.

8. COSTA N. S.; MACORIS, D. G. Citologia do lavado broncoalveolar de equinos da Policia Militar do Distrito Federal. Brazilian Journal of Veterinary Research and Animal Science, v. 44, n. 4, p.268-274, 2007. o tratamento é necessário não somente pela melhora na qualidade de vida dos animais, mas também para um melhor aproveitamento econômico do plantel.

\section{Conclusão}

Frente ao caráter assintomático da doença inflamatória das vias aéreas dos equinos de policiamento, a utilização do lavado broncoalveolar como método diagnóstico é fundamental, pois permite reconhecer, tratar e determinar uma utilização mais racional desses animais, de modo a melhorar a qualidade de vida e prolongar a utilização dos mesmos em serviço.

9. HOFFMAN, A. M. Bronchoalveolar lavage: sampling technique and guidelines for cytologic preparation and interpretation. Veterinary Clinics Equine Practice, v. 24, p. 423-435, 2008.

10.TYLER, R. D.; COWELL, R. L.; CLINKENBEARD, K. D.; MACALLISTER, C. G. Hematologic values in horses and interpretation of hematologic data. The Veterinary Clinics of North America Equine Practice, v. 3, n. 3, p. 461-484, 1987.

11.HOUSTON, D. M.; RADOSTITS, O. M. O exame clínico. In: RADOSTITS, O. M.; MAYHEW, I. G. J.; HOUSTON, D. M. Exame clínico e diagnóstico em veterinária. Rio de Janeiro: Guanabara Koogan, 2002. p. 81.

12.MCGORUM, B. C.; DIXON, P. M.; RADOSTITS, O. M.; ABBOTT, J. A. Exame clínico do trato respiratório. In: RADOSTITS, O. M.; MAYHEW, I. G. J.; HOUSTON, D. M. Exame clínico e diagnóstico em veterinária. Rio de Janeiro: Guanabara Koogan, 2002. p. 231-269.

13.DIXON, P. M. Ancillary diagnostic techniques for the investigation of equine pulmonary disease. Equine Veterinary Education, v. 9, n. 2, p. 72-80, 1997.

14.DEEGEN, E.; KLEIN, H. K. Intrapleural pressure measurement and bronchial spasmolysis tests in the horse performed with a transportable oesophageal pressure measuring instrument. Pferdeheilkunde, v. 3, n. 4, p.213-221, 1987.

15.SANCHES, A. Avaliação citológica do lavado traqueobrônquico de equinos clinicamente sadios e daqueles portadores de afecções do sistema respiratório. 1998. 148 f. Dissertação (Mestrado em Clínica Veterinária) Faculdade de Medicina Veterinária e Zootecnia, Universidade de São Paulo, São Paulo, 1998.

16. HOFFMAN, A. M.; VIEL, L. Techniques for sampling the respiratory tract of horses. The Veterinary Clinics of North America Equine Practice, v. 13, n. 3, p. 463-475, 1997.

17.MORI, E. Avaliação da função dos macrófagos alveolares após infecção experimental em cavalos (Equus caballus - L.) por herpesvírus equino tipo 1 (HVE-1). 2000. $98 \mathrm{f}$. Dissertação (Mestrado em Clínica Veterinária) - Faculdade de 
Medicina Veterinária e Zootecnia, Universidade de São Paulo, São Paulo, 2000.

18. ROSENFELD, G. Corante pancrômico para hematologia e citologia clínica. Nova combinação dos componentes do MayGrunwald e do Giemsa num só corante de emprego rápido. Memórias do Instituto Butantã, v. 20, p. 329-335, 1947.

19. MCGORUM, B. C.; DIXON, P. M.; HALLIWELL, R. E. W.; IRVING, P. Comparison of cellular and molecular components of bronchoalveolar lavage fluid harvested from different segments of the equine lung. Research in Veterinary Science, v. 55 , n. 1 , p. $57-59,1993$

20.HOFFMAN, A. M. Inflammatory airway diseases: definitions and diagnosis in the performance horse. In: ROBINSON, N. E. Current therapy in equine medicine. 5. ed. Missouri: Saunders, 2003. p. 412-416.

21.MCKANE, S. A.; CANFIELD, P. J.; ROSE, R. J. Equine bronchoalveolar lavage cytology: survey of thoroughbred racehorses in training. Australian Veterinary Journal, v. 70, n. 11, p. 401-404, 1993.

22. MCGORUM, B. C.; DIXON, P. M. The analysis and interpretation of equine bronchoalveolar lavage fluid (BALF) cytology. Equine Veterinary Education, v. 6, n. 4, p. 203-209, 1994.

23.COUËTIL, L. L.; DENICOLA, D. B. Blood gas, plasma lactate and bronchoalveolar lavage cytology analyses in racehorses with respiratory disease. Equine Veterinary Journal, v. 31, n. 530, p. 77-82, 1999. Supplement.

24.HARE, J. E.; VIEL, L. Pulmonary eosinophilia associated with increased airway responsiveness in young racing horses. Journal of Veterinary Internal Medicine, v. 12, n. 3, p. $163-$ $170,1998$.

25.SWEENEY, C. R.; ROSSIER, Y.; ZIEMER, E. L.; LINDBORG, $\mathrm{S}$. Effect of lung site and volume on results of bronchoalveolar lavage fluid analysis in horses. American Journal of Veterinary Research, v. 53, n. 8, p. 1376-1379, 1992.
26.FERRO, E.; FERRUCCI, F.; ZUCCA, E.; DI FABIO, V.; CASTOLDI, S. Arterial blood gas analysis in 53 racehorses with diagnosis of small airway inflammatory disease (SAID). Journal of Equine Veterinary Science, v. 22, n. 4, p. 165-168, 2002.

27.PIRRONE， F.; ALBERTINI, M.; CLEMENT, M. G.; LAFORTUNA, C. L. Respiratory mechanics in standardbred horses with sub-clinical inflammatory airway disease and poor athletic performance. The Veterinary Journal, v. 173, n. 1, p. 144-150, 2007.

28. MOORE, B. R. Lower respiratory tract disease. The Veterinary Clinics of North America Equine Practice, v. 12, n. 3, p. 457$472,1996$.

29.FREEMAN, K. P.; ROSZEL, J. F. Equine cytology patterns in respiratory conditions of noninfectious or unknown origin. The Compendium on Continuing Education for the Practicing Veterinarian, v. 19, n. 6, p. 755-763, 1997.

30.BEECH, J. Cytology of tracheobronchial aspirates in horses. Veterinary Pathology, v. 12, n. 3, p. 157-164, 1975.

31.FERNANDES, W. R.; MORI, E.; SANCHES, A. Avaliação citológica de lavados traqueobrônquico e broncoalveolar em cavalos clinicamente sadios pelo método de coloração de Rosenfeld. Arquivos Brasileiros de Medicina Veterinária e Zootecnia, v. 52, n. 6, p. 604-609, 2000.

32.HEWSON, J.; VIEL, L. Sampling and cytology of the respiratory tract. In: LEKEUX, P. Equine respiratory disease. Ithaca: International Veterinary Information Service, 2002. Disponível em: <http://www.ivis.org/special books/Lekeux/viel/chapter_frm.asp?LA=1>. Acesso em: 11 set. 2003 .

33.HOLCOMBE, S. J.; JACKSON, C.; GERBER, V.; JEFCOAT, A.; BERNEY, C.; EBERHARDT, S.; ROBINSON, N. E. Stabling is associated with airway inflammation in young Arabian horses. Equine Veterinary Journal, v. 33, n. 3, p. 244-249, 2001. 